Research Article

\title{
The Impact of Identity on Satisfaction toward Entrepreneurial Environment: A Case Study
}

\author{
Liu Liu $\mathbb{D}^{1}$ and Fan Tian $\mathbb{D D}^{2}$ \\ ${ }^{1}$ Department of Public Administration, Chinese Communist Party School of Nanjing, Nanjing 210046, China \\ ${ }^{2}$ Institute of Social Development, Chinese Academy of Macroeconomic Research, Beijing 100044, China \\ Correspondence should be addressed to Fan Tian; tianfan0419@sina.com
}

Received 22 May 2021; Revised 19 June 2021; Accepted 25 June 2021; Published 2 July 2021

Academic Editor: Daqing Gong

Copyright (C) 2021 Liu Liu and Fan Tian. This is an open access article distributed under the Creative Commons Attribution License, which permits unrestricted use, distribution, and reproduction in any medium, provided the original work is properly cited.

\begin{abstract}
With the evolution of economic theory and the change of actual environment, the research on returnee entrepreneurs owns new significance. This article uses Chinese returnee entrepreneurs in Beijing areas as a sample to test the halo effect after returnee entrepreneurs encounter financing expectations violation and uses the theory of identity economics to explain the cause of this halo effect. Questionnaire survey, correlation analysis, and multiple regression were used in this study. The conclusion shows that after overseas returnees encounter a violation of financing expectations, not only will they lower their satisfaction with the financing environment but also this negative sentiment will spread to the two areas of policy support environment and entrepreneurial culture environment. The halo effects produced by returnees of different identity types are different, and the halo effect produced by returnees who identify with their own talents will be more obvious.
\end{abstract}

\section{Introduction}

Driven by factors such as the continuous development of China's economy and changes in the international environment, the number of Chinese returnees and their ratio among overseas Chinese talents are on the rise. From 1978 to 2019, a total of 6.60600 Chinese students of various types studied abroad, 4.9044 million of whom had completed their studies, and 4.2317 million had returned to China after completing their studies. Against the backdrop of China's mass entrepreneurship and innovation strategy, many Chinese returnees have joined the startup boom. Compared to local counterparts, enterprises established by Chinese returnees are more innovative and play a significant role in promoting the development of local high-tech enterprises (Liu, 2010; Filatotchev, 2011) [1]. The Chinese government also recognizes the importance of Chinese returnees, and governments at all levels have put in place numerous policies to attract Chinese returnee entrepreneurs. Among them, Beijing continues to promote a series of policies such as the overseas talents gathering project, Shanghai does the same respectively through the " 20 talents", " 30 talents," and other documents, and Shenzhen continues to implement the peacock plan, Pengcheng talents plan, and other policies.

Many returnees have started successful businesses in China, but many have failed to do so. Starting a business is a very difficult process with many challenges. Every behavioral choice will directly affect the final entrepreneurial results. Research on the change of mentality of returnees' entrepreneurs when faced with difficulties such as money in the process of entrepreneurship is helpful to have a clearer understanding of the entrepreneurial process of returnees' entrepreneurs.

As the number of Chinese students studying abroad has increased year after year, overseas Chinese talents have gradually become a large social group. While the comprehensive capabilities of Chinese returnees have declined compared to those in the 20th century, recent Chinese returnees have also acquired new characteristics in terms of their views on life and values. Chinese returnee entrepreneurs, the elites among returnees, have accumulated rich human capital overseas, giving rise to theoretical and 
practical significance for research on their identity issues. On the one hand, existing research on identity lacks empirical studies based on Chinese returnees, making an empirical study on them helpful in developing theories of identity economics. On the other hand, the research findings of Wang et al. (2018) show that a halo effect would result from the violations of expectations of Chinese returnee entrepreneurs during their financing endeavors, which leaves much room for further discussions [2]. Identity economics may provide a clearer interpretation of such phenomenon.

\section{Literature Review}

Since many Chinese returnee entrepreneurs have spent many years living overseas, they have a limited understanding of China's domestic market, their knowledge of local entrepreneurial environment is lacking, and their social capital is small. As a result, they may encounter difficulties in financing, financial constraints, and long-term shortage of funding (Ebben et al., 2006; Wang, 2014) [3]. At the same time, having spent years accumulating human capital and expertise in technology and operations, Chinese returnee entrepreneurs are generally confident in the early days of their startup operations, with high expectations regarding their entrepreneurial projects. When encountering difficulties in financing, their expectations conflict with their experience in the external capital market. Such conflicts are referred to as "violations," according to the expectancy violation theory. When people's expectations are negatively violated, people are known to react with intensive negative emotions (Jussim et al., 1987; Burgoon, 1997) [4]. In the workplace, violations of expectations can reduce job satisfaction (Bandura, 2006; Latham et al., 2006) [5], organizational trust (Dulac et al., 2008) [6], and job performance (Dulac et al., 2009) [7] of employees, while increasing their intention to resign (Tekleab, 2005) [8]. An empirical study on Chinese returnees conducted by Wang Shuyang et al. [2] in 2018 arrived at an interesting conclusion: when Chinese returnee entrepreneurs face violations of expectations during financing endeavors, their satisfaction toward the financing environment for entrepreneurship would decrease, and there would also be a halo effect which reduces their satisfaction toward government supporting policies and the cultural environment for entrepreneurship.

Since the 1950s, radical social changes have taken place in many countries around the world. Identity and identification have been drawing ever more attention from the Western social sciences community (Gleason, 1983; Brubaker et al., 2000) [9]. In economics, the 2008 financial crisis and its sustained global impact have been inspiring economists to reflect on their discipline, particularly regarding "economic imperialism" (Gu Yan, 2017) [10]. In this process, identity economics, a concept that has emerged in the recent 20 years, has been receiving increasingly greater recognition. Some even refer to it as "the Rosetta Stone of economics" (Liang Jie, 2012) [11]. After years of research, Akerlof et al. have devised a complete theoretical framework for identity economics, in which the formation of a person's identity is a process of utility maximization through actions. The increase or decrease in one's sense of identity leads to a change in utility. Identity influences not only the choices of individuals, but also the effect of implementing various policies, which provides a new perspective for interpreting social issues with economic models (Akerlof, 2000, 2002, 2007, and 2013 Chinese version) [12]. Further studies conducted by Mori (2014 Chinese version) analyze the diversity of identities and the negative consequences brought on to society by a homogenous identity, which demonstrates the significance of one's identity [13].

The theoretical model of identity economics is comprised of template models and identity factors, in which the former describes the behavior choices of people, while the latter includes social categories, norms, and ideals, as well as utility losses and gains of identity. In terms of social categories, people are divided into "insiders" and "outsiders" holding different beliefs. When insiders engage in behaviors that deviate from the group, they would suffer from additional losses in utility; the same is true for outsiders. For example, statistics show that a common "lackey" in a Chicago gang earns as much money as someone working in McDonald's, though the latter takes far fewer risks, making crimes extremely not worthwhile. Even so, crime levels among lower-class Black Americans remain high. The loss in utility brought about by identity provide a good interpretation of such phenomena (Akerlof, 2013 Chinese version) [14]. In recent years, Chinese scholars have also begun to use identity economics theories to conduct research into incentive mechanisms in public sectors (Lu, 2016) [15] and empirical studies on the relationship between the identity of government officials and local economic growth (Li Shujuan et al., 2016) [16].

\section{Research Methodology}

\subsection{Hypotheses Development}

3.1.1. Violations of Financing Expectations and Satisfaction toward the Financing Environment for Entrepreneurship. Entrepreneurs may face a series of difficulties in starting a business. For startups, the primary one is usually funding. Particularly, many Chinese returnee entrepreneurs who have spent years living overseas may have much knowledge of advanced technologies and experience in operations and management (Miao Qi et al., 2015) [17], but at the same time, they may be lacking financing channels. Most Chinese returnees who choose to start businesses in China are confident in their projects, and such confidence would be manifested in their financing expectations. When Chinese returnee entrepreneurs encounter violations of their financing expectations, they would attribute such violations to various reasons. According to attribution theory, people tend to adopt situational attribution rather than attributing the violations to their own flaws (Malle, 2006) [18].

Based on research findings of Gnyawali et al. (1994) [19] and Wang Shuyang et al. (2018) [20], the authors believe that the entrepreneurial environment is defined by three main factors, namely, financing for entrepreneurship, policy support, and entrepreneurial culture. The authors also 
believe that when violations of financing expectations happen, Chinese returnee entrepreneurs would first attribute the cause for such violations to the external financing environment, therefore becoming discontented with the financing environment for entrepreneurship.

(1) Hypothesis 1. Violations of financing expectations have a significant negative impact on the satisfaction of Chinese returnee entrepreneurs toward the financing environment for entrepreneurship.

\subsubsection{Violations of Financing Expectations and Satisfaction} toward Other Environmental Factors for Entrepreneurship. According to the halo effect, people tend to overgeneralize their evaluation of a certain aspect to other related aspects, producing a biased evaluation of a certain matter as a whole. Therefore, the negative emotions resulting from violations of financing expectations not only are visible in the discontent with the financing environment for entrepreneurship but also extend to other aspects (Wang Shuyang et al., 2018) [5].

The Chinese government has been attaching great importance to Chinese returnees. Particularly, against the backdrop of mass entrepreneurship and innovation policy, it has provided abundant supporting policies for Chinese returnee entrepreneurs, such as innovation funds encouraging scientific research and relevant service packages for entrepreneurship. When Chinese returnee entrepreneurs encounter violations of their financing expectations, situational attribution would result in their strong discontent with the insight and decision-making of the external capital market, with the belief that their projects are underrated. The authors believe that when Chinese returnee entrepreneurs encounter financing failures, they are highly likely to attribute the failures to the incompetency and ineffective organization of the government.

Cultures related to entrepreneurship are generally manifested in the support and encouragement of local residents for innovation and entrepreneurship, as well as their tolerance of entrepreneurial failures (Duan Limin et al., 2012) [7]. The author also holds the opinion that when Chinese returnee entrepreneurs with limited understanding of the cultural environment for entrepreneurship in China encounter violations of their financing expectations, they would view the local capital market as risk-averse and intolerant toward the disadvantages of their entrepreneurial projects. They would put the blame on the local cultural environment for entrepreneurship.

(1) Hypothesis 2-1. The halo effect would cause violations of financing expectations to have a significant negative impact on the satisfaction of Chinese returnee entrepreneurs toward the policy support environment.

(2) Hypothesis 2-2. The halo effect would cause violations of financing expectations to have a significant negative impact on the satisfaction of Chinese returnee entrepreneurs toward the entrepreneurial cultural environment.
3.1.3. Identity and the Halo Effect. George A. Akerlof, winner of the Nobel Economics Prize, was the first to introduce social identity and other behavioral norms closely related to identity into utility functions, an extension of the traditional individual decision-making models. His theory assumes that society is comprised of different groups $(\mathrm{C})$, while the characteristics $\left(\varepsilon_{\mathrm{i}}\right)$ and actions $\left(a_{i}\right)$ of each individual determine the group $\left(c_{i}\right)$ to which an individual belongs and form the corresponding identity $\left(I_{i}\right)$. Each group has the norms for best practices $(\mathrm{P})$. If the actual actions an individual deviates from such norms, the individual would feel anxious and uncomfortable, thereby reducing utility. At the same time, due to the externalities of identity, the utility of other members in the group would also be reduced. As a result, other members may respond negatively, hence triggering a series of behavioral games. Therefore, the utility of an individual is decided by not only his own actions $\left(a_{i}\right)$, but also the actions of others in the group $\left(a_{-i}\right)$ and the identity of the individual $\left(I_{i}\right)$, which may be represented in the following equation:

$$
U_{i}=\left(a_{i}, a_{-i}, I_{i}\right),
$$

where $I_{i}$ is affected by the actions of the individual $\left(a_{i}\right)$, the actions of others $\left(a_{-i}\right)$, the category of the group $\left(c_{i}\right)$, the characteristics of the individual $\left(\varepsilon_{i}\right)$, and the norms for best practices $(P)$, which may be represented in the following equation:

$$
I_{i}=\left(a_{i}, a_{-i}, c_{i}, \varepsilon_{i}, P\right),
$$

where the impact of $I_{i}$ on $U_{i}$ is referred to as identity gains and losses. Under fixed $c_{i}$, $\varepsilon_{i}$, and $P$, an individual could adjust his own actions $\left(a_{i}\right)$ to achieve utility maximization. According to the identity theory of Akerlof, Chinese returnees may also be divided into "insiders" and "outsiders" in terms of social categories. When Chinese returnee entrepreneurs engage in actions that deviate from the "insider" group, they are subject to additional losses in utility. The author believes that such losses in utility would contradict their cognition and aggravate the halo effect.

(1) Hypothesis 3. Identity would aggravate the halo effect of Chinese returnee entrepreneurs after violations of financing expectations.

\subsection{Design of Questionnaires}

3.2.1. Design of the Questions on Violations of Financing Expectations. The way to conduct survey on violations of financing expectations is to let Chinese returnee entrepreneurs answer the question "What is the major difficulty in your entrepreneurial endeavors?". Among the options, "lack of funding" is deemed as the proxy for violations of financing expectations. For the purpose of this study, the dummy variables 0 and 1 are used to measure violations of financing expectations, with 1 representing that the enterprise established by the Chinese returnee entrepreneur has encountered violations of financing expectations, while 0 means that it has not. 
3.2.2. Design of the Question on Identity. The core of the question on identity is to categorize Chinese returnees into "insiders" and "outsiders." The author believes that the criterion for this question is whether the Chinese returnee recognizes his or her identity as a talent. An entrepreneur may make completely different decisions in the entrepreneurial process based on whether the entrepreneur identifies himself as a talent and have different value judgments on the consequences of the decisions made. Therefore, the question on identity in this study is "As a Chinese returnee, do you identify yourself as a talent?" The dummy variables 0 and 1 are used to measure identity, with 1 representing that the Chinese returnee entrepreneur identifies himself as a talent, while 0 means that he or she does not.

\subsubsection{Design of the Scale for Satisfaction of the Entrepre-} neurial Environment. The scales for satisfaction of the entrepreneurial environment mainly draw from Wang Shuyang's approach (2018). All questions adopt the FivePoint Likert Scale, with the options being "strongly disagree," "disagree," "neutral," "agree," and "strongly agree" from 1 to 5 . The reliability and validity of the scales are verified using $\mathrm{KMO}$ and Cronbach's Alpha values. The results show that the KMO values for all scales are above 0.8 , and Cronbach's Alpha values for all scales are above 0.9 , indicating the scales have good reliability and validity (Table 1 ).

3.2.4. Control Variables. The age, marital status, household register (local or nonlocal), field of study, time since return, work experience (prior to entrepreneurship), and other aspects of each Chinese returnee surveyed are also investigated. Such information serves as control variables in the study.

3.3. Data Collection. Beijing is the capital of China, as well as the cultural center and scientific and technological innovation center, which has gathered a large number of returnees entrepreneurs for a long time. Therefore, the questionnaire survey was carried out in Beijing. With the support from Research on Factors Influencing the Willingness of Overseas Talents to Come Back (no. 16CSH044), a youth project of the National Social Science Fund of China, and with the help of an association in Beijing, questionnaires of this study were distributed in two rounds: 100 questionnaires in the first round from June to August 2019, and another 600 in the second round from October to December 2019. Out of the 700 questionnaires, 634 were collected, with a response rate of $90.57 \%$. After excluding repeat and obviously illogical submissions, a total of 595 valid questionnaires were obtained, with a valid rate of $93.85 \%$. Basic information collected in the questionnaires is shown in Table 2.

\section{Research Results}

4.1. Correlation Analysis. The results of correlation analysis show strong correlations (Table 3) between satisfaction toward the financing environment for entrepreneurship, satisfaction toward the policy support environment, and satisfaction toward the cultural environment for entrepreneurship, indicating that Chinese returnee entrepreneurs see some similarities between the three aspects of the entrepreneurial environment. Violations of financing expectations have significant negative correlations with the three, and the same negative correlation is observed between identity and the three. These observations are in line with the three hypotheses of the study. At the same time, the correlation analysis results also show that the correlation between the variables such as gender, education background, age, overseas time, and working experience and the dependent variables is less than the correlation between the variables such as financing expectation violation and identity identification.

4.2. Preliminary Regression Analysis. The results of preliminary regression analysis are shown in Table 4 . Models 1, 3, and 5 test the influence of the control variables on the three dependent variables, namely, satisfaction toward the financing environment for entrepreneurship, satisfaction toward the policy support environment, and satisfaction toward the cultural environment for entrepreneurship. Among the control variables, time spent living overseas and highest education have significant negative influence on the dependent variables. Models 2, 4, and 6 test the impact of violations of financing expectations on the three dependent variables. From the test results of Model 2, the coefficient of violations of financing expectations is -0.422 with $p<0.01$, indicating significant test results. In addition, the $\triangle R^{2}$ of Model 2 is 0.035 , indicating that, with the introduction of independent variables, the overall explanatory power of Model 2 on dependent variables is $3.5 \%$ higher than that of Model 1. The goodness of fit is favorable, providing sufficient support for Hypothesis 1 . From the test results of Models 4 and 6 , the coefficients of violations of financing expectations are -0.348 and -0.299 , respectively, with $p<0.01$, indicating significant test results. The $\triangle R^{2}$ values of Models 4 and 6 are 0.024 and 0.029 , respectively, indicating that, with the introduction of independent variables, the overall explanatory powers of the two models on dependent variables are $2.4 \%$ and $2.9 \%$ higher than those of Models 3 and 5. The goodness of fit is favorable, providing sufficient support for $\mathrm{Hy}$ pothesis 2 .

4.3. Grouped Regression Analysis. To further verify the impact of identity on the halo effect, the author categorizes the sample based on whether the respondents identify themselves as talents. Regression analysis is conducted with satisfaction toward the financing environment for entrepreneurship, satisfaction toward the policy support environment, and satisfaction toward the cultural environment for entrepreneurship as dependent variables, the results of which are shown in Table 5 . The dependent variables are satisfaction toward the financing environment for entrepreneurship for Models 7 and 8, satisfaction toward the policy support environment for Models 9 and 10, and 
TABLE 1: Reliability and validity of scales for satisfaction toward the entrepreneurial environment.

\begin{tabular}{|c|c|c|c|}
\hline Variable & Question & $\mathrm{KMO}$ & $\begin{array}{c}\text { Cronbach } \\
\alpha\end{array}$ \\
\hline $\begin{array}{l}\text { Financing environment for } \\
\text { entrepreneurship }\end{array}$ & $\begin{array}{l}\text { (1) There is sufficient local venture capital provided for startups and growth } \\
\text { companies } \\
\text { (2) There is sufficient local credit fund provided for startups and growth companies } \\
\text { (3) There are sufficient local government subsidies provided for startups and } \\
\text { growth companies } \\
\text { (4) There is sufficient local individual funding (apart from the founder of the } \\
\text { company) provided for startups and growth companies }\end{array}$ & 0.843 & 0.915 \\
\hline Policy support environment & $\begin{array}{l}\text { (5) The government has policies in place (such as public procurement) offering } \\
\text { preferential treatment to newly established companies } \\
\text { (6) The local government has formulated preferential supporting policies for } \\
\text { startups and growth companies } \\
\text { (7) Newly established companies are able to obtain the required approvals and } \\
\text { permits within a short period of time } \\
\text { (8) Taxes are not a burden for startups and growth companies } \\
\text { (9) Government regulations on taxation and other matters for startups and growth } \\
\text { companies are stable } \\
\text { (10) Startups and growth companies have no difficulty in coping with government } \\
\text { agencies or rules and regulations } \\
\text { (11) Startups and growth companies are able to obtain extensive government } \\
\text { support through agencies }\end{array}$ & 0.837 & 0.922 \\
\hline $\begin{array}{l}\text { Cultural environment for } \\
\text { entrepreneurship }\end{array}$ & $\begin{array}{l}\text { (12) The local culture encourages creation and innovation } \\
\text { (13) Local culture is supportive of entrepreneurship and does not settle for less } \\
\text { (14) Local culture is tolerant of entrepreneurial failures }\end{array}$ & 0.801 & 0.919 \\
\hline
\end{tabular}

TABLE 2: Basic information about the sample.

\begin{tabular}{|c|c|c|c|c|c|c|c|}
\hline Item & Ratio (\%) & Item & Ratio (\%) & Item & Ratio (\%) & Item & Ratio (\%) \\
\hline Age & & Ph.D. & 22.9 & \multicolumn{2}{|c|}{ Gender } & $8-10$ years & 10.8 \\
\hline Below 25 & 5.2 & \multicolumn{2}{|c|}{ Field of study } & Male & 55.6 & More than 10 years & 13.6 \\
\hline $26-30$ & 25 & Science & 68.2 & Female & 44.4 & \multicolumn{2}{|c|}{ Work experience } \\
\hline $31-35$ & 31.8 & Arts & 31.8 & \multicolumn{2}{|c|}{ Household register } & No experience & 14.5 \\
\hline $36-40$ & 20.5 & \multicolumn{2}{|c|}{ Marital status } & Local & 46.4 & Less than 2 years & 18.1 \\
\hline $41-50$ & 13.6 & Married & 52.3 & Nonlocal & 53.6 & $2-4$ years & 18.1 \\
\hline Above 50 & 3.9 & Single & 43.2 & \multicolumn{2}{|c|}{ Time since return } & $4-6$ years & 5.8 \\
\hline \multicolumn{2}{|c|}{ Highest education } & Divorced & 4.5 & Less than 2 years & 22.7 & $6-8$ years & 10.9 \\
\hline Diploma & 2.7 & \multicolumn{2}{|c|}{ Number of children } & 2-4 years & 22.7 & $8-10$ years & 22.7 \\
\hline Bachelor's degree & 24.7 & One and above & 44 & $4-6$ years & 14.5 & More than 10 years & 9.9 \\
\hline Master's degree & 49.7 & No children & 56 & $6-8$ years & 15.8 & & \\
\hline
\end{tabular}

TABLE 3: Correlation analysis.

\begin{tabular}{llllllllll}
$(1)$ & $(2)$ & $(3)$ & $(4)$ & $(5)$ & $(6)$ & $(7)$ & $(8)$ & $(9)$ & $(10)$ \\
\hline
\end{tabular}

(1) Financing environment for entrepreneurship

(2) Policy support environment 1

(3) Cultural environment for entrepreneurship

(4) Violations of financing expectations

(5) Identity

(6) Gender

(7) Highest education

(8) Age

(9) Time spent living overseas (2) (3) (4) (5) (6) $(7)$ 10)

(10) Work experience

$\begin{array}{ccccccccccc}0.699^{* * *} & 1 & & & & & & & & \\ 0.712^{* * *} & 0.687^{* * *} & 1 & & & & & & & \\ -0.423^{* * *} & -0.276^{* * *} & -0.317^{* * *} & 1 & & & & & & & \\ -0.401 & -0.375 & -0.324^{* *} & 0.298^{* * *} & 1 & & & & & \\ -0.102^{*} & -0.102 & -0.004 & -0.053 & 0.113 & 1 & & & & \\ -0.234^{*} & -0.197^{* *} & -0.231^{* *} & 0.170^{*} & 0.113^{* *} & -0.003 & 1 & & & \\ 0.112^{*} & 0.094^{*} & -0.098^{*} & -0.037 & 0.104 & -0.103 & -0.025 & 1 & & \\ -0.134^{*} & -0.142^{* *} & -0.149^{*} & 0.171^{*} & -0.196^{* *} & -0.107 & 0.379^{*} & 0.226^{* *} & 1 & \\ -0.102^{*} & -0.119 & 0.093 & 0.123^{*} & -0.079 & -0.108 & 0.117^{*} & 0.154^{*} & 0.229 & 1\end{array}$

Note: “*," “**," and “***” indicate 10\%,5\%, and 1\% levels of significance (according to the results of correlation analysis). 
TABLE 4: Preliminary regression analysis.

\begin{tabular}{|c|c|c|c|c|c|c|}
\hline Variable & Model 1 & Model 2 & Model 3 & Model 4 & Model 5 & Model 6 \\
\hline Constant & $3.102^{* * *}$ & $3.573^{* * *}$ & $1.794^{* * *}$ & $3.079^{* * *}$ & $2.321^{* *}$ & $3.192^{* * *}$ \\
\hline \multicolumn{7}{|c|}{ Control variables } \\
\hline Age & 0.015 & 0.021 & 0.015 & 0.024 & -0.031 & -0.000 \\
\hline Gender & -0.018 & -0.007 & -0.024 & -0.009 & 0.006 & 0.031 \\
\hline Time spent living overseas & $-0.102^{*}$ & $-0.114^{*}$ & $-0.117^{*}$ & $-0.092^{*}$ & $-0.082^{*}$ & $-0.073^{*}$ \\
\hline Work experience & -0.107 & $-0.043^{*}$ & 0.032 & 0.096 & -0.089 & -0.174 \\
\hline Highest education & $-0.125^{*}$ & $-0.113^{*}$ & $-0.195^{*}$ & $-0.213^{*}$ & $-0.127^{*}$ & $-0.172^{*}$ \\
\hline \multicolumn{7}{|c|}{ Independent variable } \\
\hline Violations of financing expectations & - & $-0.422^{* * *}$ & - & $-0.348^{* * *}$ & - & $-0.299^{* *}$ \\
\hline$F$ & $2.95^{* * *}$ & $4.11^{* * *}$ & $3.57^{* * *}$ & $4.59^{* * *}$ & $3.39^{* * *}$ & $3.84^{* * *}$ \\
\hline$R^{2}$ & 0.328 & 0.363 & 0.286 & 0.310 & 0.259 & 0.288 \\
\hline$\Delta R^{2}$ & - & 0.035 & - & 0.024 & - & 0.029 \\
\hline$N$ & 595 & 595 & 595 & 595 & 595 & 595 \\
\hline
\end{tabular}

Note: “*," «**," and “***” indicate $10 \%, 5 \%$, and $1 \%$ levels of significance.

TABLE 5: Grouped regression analysis.

\begin{tabular}{|c|c|c|c|c|c|c|}
\hline Variable & Model 7 & Model 8 & Model 9 & Model 10 & Model 11 & Model 12 \\
\hline Constant & 3.233 & 3.199 & 2.765 & 3.102 & 3.005 & 3.223 \\
\hline \multicolumn{7}{|c|}{ Control variables } \\
\hline Age & 0.018 & $0.02^{*}$ & 0.021 & 0.007 & $0.003^{*}$ & 0.01 \\
\hline Gender & -0.005 & 0.002 & 0.011 & -0.006 & 0.027 & 0.032 \\
\hline Time spent living overseas & $-0.179^{* *}$ & $-0.102^{*}$ & $-0.112^{* *}$ & $-0.089^{*}$ & $-0.098^{* *}$ & $-0.065^{*}$ \\
\hline Work experience & 0.012 & $0.023^{*}$ & 0.102 & 0.087 & -0.098 & -0.104 \\
\hline Highest education & $-0.123^{*}$ & $-0.119^{* *}$ & $-0.233^{*}$ & $-0.207^{*}$ & $-0.194^{* *}$ & $-0.168^{*}$ \\
\hline \multicolumn{7}{|c|}{ Independent variable } \\
\hline Violations of financing expectations & $-0.497^{* * *}$ & $-0.405^{* * *}$ & $-0.389^{* * *}$ & $-0.327^{* * *}$ & $-0.335^{* * *}$ & $-0.286^{* * *}$ \\
\hline F & 4.32 & 4.28 & 4.77 & 4.63 & 3.89 & 3.96 \\
\hline$R^{2}$ & 0.394 & 0.289 & 0.351 & 0.339 & 0.306 & 0.303 \\
\hline$\Delta R^{2}$ & 0.031 & 0.026 & 0.041 & 0.029 & 0.028 & 0.025 \\
\hline$N$ & 595 & 595 & 595 & 595 & 595 & 595 \\
\hline
\end{tabular}

Note: “*”, “**," and “***” indicate $10 \%, 5 \%$, and $1 \%$ levels of significance. The $\Delta R^{2}$ values of Models 7 and 8 correspond to Model 2, and that of Models 9 and 10 correspond to Model 4, while that of Models 11 and 12 correspond to Model 6.

satisfaction toward the cultural environment for entrepreneurship for Models 11 and 12. Models 7, 9, and 11 use the respondents who identify themselves as talents as the sample, while Models 8, 10, and 12 use those who do not.

The results show that the absolute value of the coefficient of violations of financing expectations in Model 7 $\left(\triangle R^{2}=-0.497, p<0.01\right)$ is increased as compared to the benchmark model, i.e., Model 2, indicating significant test results; that in Model $9\left(\triangle R^{2}=-0.389, p<0.01\right)$ is increased as compared to the benchmark model, i.e., Model 4 , indicating significant test results; that in Model 11 $\left(\triangle R^{2}=-0.335, p<0.01\right)$ is increased as compared to the benchmark model, i.e., Model 4 , indicating significant test results. The $\triangle R^{2}$ values of Models $7,8,9,10,11$, and 12 are $0.031,0.026,0.041,0.029,0.028$, and 0.025 , respectively, indicating that, after grouping based on identity, the explanatory powers of the models are further improved. $R^{2}$ of Model 7, Model 9, and Model 11 are all larger than those of Model 8, Model 10, and Model 12, indicating that the strength of the model is stronger when the returnees who identify with their talent status are taken as the sample. Hypothesis 3 is fully supported.

\section{Discussions and Conclusions}

The conclusion of this study, which takes Chinese returnee entrepreneurs in Beijing areas as its sample, verifies the halo effect arising after Chinese returnee entrepreneurs encounter violations of financing expectations proposed by Wang Shuyang et al. (2018) [21]. When they encounter such violations, they are first discontented with the financing environment for entrepreneurship, and their discontent would spread further to lower their satisfaction of the policy support environment and the cultural environment for entrepreneurship. The study then further elaborates on this halo effect using theories of identity economics, with a conclusion indicating that Chinese returnee entrepreneurs who identify themselves as talents, when encountering violations of financing expectations, would produce more negative evaluations on the financing environment for entrepreneurship, the policy support environment, and the cultural environment for entrepreneurship with a more apparent halo effect.

Over the years, Chinese media coverage of Chinese returnees has been focusing on Chinese returnee entrepreneurs and elites. In fact, the true image of Chinese 
returnees has not been fully presented (Zheng Luhong, 2014) [22-24]. Though Chinese returnees are often and widely referred to as "talents" in China, their average capabilities have declined as barriers to going study overseas continue to be lifted. At the same time, due to continual setbacks in their careers in China, many Chinese returnees have begun to doubt their identity as talents. For this group, due to the huge number of people and the gradual decline in their comprehensive capabilities, "Chinese returnee talents" have become "outsiders" in the group. As Chinese returnee entrepreneurs are relative elites in the group, those who identify themselves as talents are more inclined to attribute setbacks in their entrepreneurial endeavors in China to the external environment. This conclusion precisely demonstrates the additional losses in utility highlighted in the theories of identity economics.

The theoretical contribution of the study lies in verifying that the impact of violations of expectations is subject to amplifying and transferring effects, with new interpretations for this halo effect provided using the theories of identity economics to increase the explanatory power of such theories. This study only focuses on Chinese returnee entrepreneurs' evaluation of their entrepreneurial environment, with no analysis into the realities of the capital market, government policies, and the cultural environment. However, from the conclusions provided by this study, enhancing communication with Chinese returnees and implementing more targeted policies would facilitate entrepreneurial endeavors of Chinese returnees and eventually promote local economic development. Future researchers may find it interesting to explore the following two points: first, it is challenging to achieve an absolutely reasonable random sampling of Chinese overseas entrepreneurs; with the constant renewal of samples, a more convincing conclusion could be formed gradually. Second, the authors believe that, apart from simply dividing identity into "insiders" and "outsiders," a more diverse categorization could be explored in the theories of identity economics; this approach could potentially further enrich the theories of identity economics in future research.

\section{Data Availability}

The data in questionnaires of this study were distributed in two rounds: 100 questionnaires in the first round from June to August 2019 and another 600 in the second round from October to December 2019. Out of the 700 questionnaires, 634 were collected, with a response rate of $90.57 \%$. After excluding repeat and obviously illogical submissions, a total of 595 valid questionnaires were obtained, with a valid rate of $93.85 \%$.

\section{Conflicts of Interest}

The authors declare that they have no conflicts of interest.

\section{Acknowledgments}

This paper is part of the Research on Factors Influencing the Willingness of Overseas Talents to Return (no. 16CSH044), a youth project of the National Social Science Fund of China.

\section{References}

[1] X. Liu, J. Lu, I. Filatotchev, T. Buck, and M. Wright, "Returnee entrepreneurs, knowledge spillovers and innovation in hightech firms in emerging economies," Journal of International Business Studies, vol. 41, no. 7, pp. 1183-1197, 2010.

[2] S. Y. Wang, R. Wu, and X. D. Gao, "The halo effect after funding expectancy violation-research in satisfactions with the entrepreneurial environment of returnee entrepreneurs," Studies in Science of Science, vol. 36, no. 3, pp. 484-492, 2018.

[3] J. Ebben and A. Johnson, "Bootstrapping in small firms: an empirical analysis of change over time," Journal of Business Venturing, vol. 21, no. 6, pp. 851-865, 2006.

[4] L. Jussim, L. M. Coleman, and L. Lerch, "The nature of stereotypes: a comparison and integration of three theories," Journal of Personality and Social Psychology, vol. 52, no. 3, pp. 536-546, 1987.

[5] A. Bandura, Social Foundations of Thought and Action, Prentice-Hall, Englewood Cliffs, NJ, USA, 1986.

[6] T. Dulac, J. A.-M. Coyle-Shapiro, D. J. Henderson, and S. J. Wayne, "Not all responses to breach are the same: the interconnection of social exchange and psychological contract processes in organizations," Academy of Management Journal, vol. 51, no. 6, pp. 1079-1098, 2008.

[7] L. M. Duan and Y. P. Du, "Influence of entrepreneurial environment on entrepreneurial intention of college students: re-examining GEM model," Technology Economics, vol. 10, no. 10, pp. 64-70, 2012.

[8] A. G. Tekleab, R. Takeuchi, and M. S. Taylor, "Extending the chain of relationships among organizational justice, social exchange, and employee reactions: the role of contract violations," Academy of Management Journal, vol. 48, no. 1, pp. 146-157, 2005.

[9] I. Filatotchev, X. Liu, J. Lu, and M. Wright, "Knowledge spillovers through human mobility across national borders: evidence from Zhongguancun science park in China," Research Policy, vol. 40, no. 3, pp. 453-462, 2011.

[10] Y. Gu, "On the new west and the end of economic imperialism," China State Finance, vol. 11, no. 3, pp. 78-79, 2017.

[11] J. Liang, "Identity: rosetta stone tablet in economics", 21st century economic report," 2012.

[12] G. A. Akerlof and R. E. Kranton, "Economics and identity," Quarterly Journal of Economics, vol. 115, no. 3, pp. 715-753, 2000.

[13] J. K. Burgoon, "Interpersonal expectations, expectancy violations, and emotional communication," Journal of Language and Social Psychology, vol. 12, no. 2, pp. 30-48, 1993.

[14] G. A. Akerlof and R. Kranton, "Identity economics," The Economists' Voice, vol. 7, no. 2, p. 112, 2007.

[15] Z. Lu, "Incentive and restraint mechanism in the public sector from the perspective of identity economics: a review of identity economics: how identity shapes our work, pay and happiness," Public Management Review, vol. 34, no. 2, p. 34, 2016.

[16] S. Li and X. Xu, "Identity and economic growth," Economics: Quarterly, vol. 15, no. 3, pp. 941-962, 2016.

[17] Q. Miao, Y. Bao, and Y. Liu, "Impacts of human and technological capitals on the intention to start business," Studies in Science of Science, vol. 33, no. 7, pp. 1035-1042, 2015.

[18] B. F. Malle, "The actor-observer asymmetry in attribution: a (surprising) meta-analysis," Psychological Bulletin, vol. 132, no. 6, pp. 895-919, 2006.

[19] D. R. Gnyawali and D. S. Fogel, "Environments for entrepreneurship development: key dimensions and research 
implications," Entrepreneurship Theory and Practice, vol. 18, no. 4, pp. 43-62, 1994.

[20] A. George and R. Clanton, Identity Economics, CITIC Press, Beijing, China, 2013.

[21] D. Wang, "Activating cross-border brokerage," Administrative Science Quarterly, vol. 60, no. 1, pp. 133-176, 2015.

[22] L. Fu and Y. Dong, "Research on internet search data in China's social problems under the background of big data," Journal of Logistics, Informatics and Service Science, vol. 5, no. 2, pp. 55-67, 2018.

[23] J. Du, Q. Li, F. Qiao, and L. Yu, "Estimation of vehicle emission on mainline freeway under isolated and integrated ramp metering strategies," Environmental Engineering and Management Journal, vol. 17, no. 2, pp. 1237-1248, 2018.

[24] J. Du, F. Qiao, and L. Yu, "Temporal characteristics and forecasting of PM2.5 concentration based on historical data in Houston, USA," Resources, Conservation and Recycling, vol. 147, no. 3, pp. 145-156, 2019. 